\title{
Marcadores culturais, espaços sagrados e as representações identitárias missioneiras no prata
}

\section{Cultural Markers, Sacred Spaces and Missionary Identiary Representations in Silver}

\author{
Muriel Pinto* Carmen Regina Dorneles Nogueira** \\ Ronaldo Bernardino Colvero***
}

Resumo: As cidades fronteiriças de São Borja-Brasil e Santo Tomé-Argentina tiveram 0 inicio de sua formação territorial a partir da implementação das Reduções Jesúítico-Guarani (séc. XVIII). Este período enraizou modos de vida, saberes, crenças e marcadores arquitetônicos na região. Para tanto, o estudo objetivou realizar uma reflexão identitária numa região histórica do Prata, problematizando como que as representações sociais e os marcadores culturais missioneiros, acabam por reproduzir narrativas identitárias regionais. Como resultados parciais sustenta-se que a identidade missioneira regional, por mais que venha sofrendo com alteridades estancieiras, ainda mantém práticas tradicionais vivenciadas, a partir de ritualidades, crenças sagradas e míticas, e através da afirmação discursiva e simbólica da musicalidade missioneira.

PaLAVRAS-CHAVE: Identidade missioneira; Espaços sagrados; Representações sociais; Marcadores territoriais; Fronteira Brasil-Argentina.

ABSTRACT: The border cities of São Borja-Brasil and Santo Tomé-Argentina began their territorial formation from the implementation of the Jesuit-Guarani Reductions (17th century). This period took root in ways of life, knowledge, beliefs and architectural markers in the region. To this end, the study aimed to carry out an identity reflection in a historical region of Prata, questioning how social representations and missionary cultural markers end up reproducing regional identity narratives. As partial results, it is argued that the regional missionary identity, no matter how much it has suffered from stagnant alterities, still maintains traditional practices experienced, based on rituals, sacred and mythical beliefs, and through the discursive and symbolic affirmation of missionary musicality.

KEY wORDS: Mission Identity: Sacred spaces; Social representations; Territorial markers; Brazil-Argentina border.

Recibido: 7 de agosto de 2019

Aceptado: 13 de abril de 20120

* Universidad Federal de la Pampa (murielpinto@unipampa.edu.br).

** Universidad Federal de la Pampa (unipampa-brasilcr.unipampa@hotmail.com).

*** Universidad Federal de la Pampa (ronaldocolvero@unipampa.edu.br). 
ESPAÇOS SAGRADOS, RITUALIDADES

E PROFANIAS MISSIONEIRAS

Os ritos e práticas que foram ligados a certos modos de atividade de um grupo podem persistir quando de existência que lhes serviram de suporte desaparecem. Seu sentido se perdeu (Bonemaison 2012: 320).

citação acima traz uma reflexão pertinente, pois expõem como
certas práticas sociais, ritualidades, saberes e crenças são enraí-
zadas nos espaços sociais. Nos últimos anos os estudos da Geo-
grafia Social e da História social na região histórica das Missões Jesuítico-Guarani, vem despertando linhas de discussões sobre como as crenças e manifestações profano-religiosas podem ter relação com os processos de reconhecimento e enraizamento social de elementos do período reducional Jesuítico-Guarani.

Figura 1.

Localização das Cidades Gêmeas de São Borja-Brasil/ Santo Tomé-Argentina

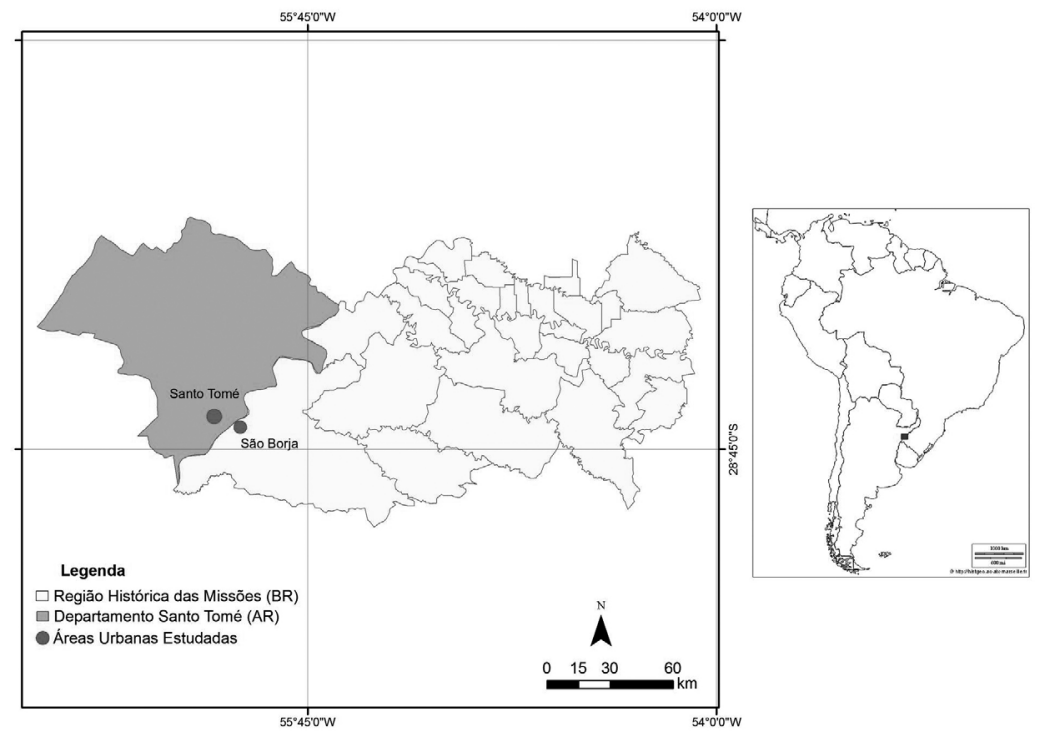

Fonte: Elaborado por Nola Gamalho (2015). 
O recorte espacial em estudo possui uma importância geopolítica para a região do Prata da América do Sul, pois tanto São Borja como Santo Tomé eram antigas Reduções Guaranis fundadas nas margens do rio Uruguai no século XVII. Estes povoados foram aglomerados urbanos construídos pela Companhia de Jesus, organismo vinculado aos Jesuítas. Entre as bacias dos rios Paraguai, Paraná e Uruguai haviam entorno de trinta Reduções Jesuítico-Guaranis. As Reduções foram espaços sociais que se constituíram a partir da religiosidade, da arte e de estratégias territoriais. (ver figura 1).

No que toca a história da arte e suas relações com as religiosidades locais destaca-se a importância das representações artísticas para a afirmação de uma evangelização e de um projeto político-territorial Jesuíta no Prata. Em relação as imaginárias e algumas estruturas urbanas de São Borja e Santo Tomé destaca-se a imponência artística do Barroco com a influência europeia (muitas reduções Jesuítico-Guaranis foram planejadas por arquitetos italianos de época), assim como observa-se imagens com características do Barroco missioneiro (imagens elaboradas pelos nativos com aprendizados advindos da arquitetura italiana).

Assim como em toda a região missioneira, nota-se nos espaços fronteiriços de São Borja e Santo Tomé, o culto e a sacralização de ritualidades sagradas e profanas vinculadas a marcadores reducionais, como as imaginárias santas e estruturas urbanas remanescentes de época. A manutenção de crenças tradicionais religiosas, como a exaltação a santos, constituição de oratórios, e a realização de diversas procissões pelas áreas urbanas. Também se mantém o costume e a crença na benzedura para o combate a diversos problemas de saúde, o que expõem a exaltação as crenças espirituais (Pinto 2015).

Segundo Pinto (2015) nesta região de fronteira entre São Borja-Brasil e Santo Tomé-Argentina "observa-se diversas procissões que até hoje ainda são ritualizadas e praticadas, como: São João Batista, Nossa Senhora de Navegantes, São Francisco de Borja (São Borja), e procissão de Imaculada Concepción de Itati e Gauchito Gil (Santo Tomé)”. No quem toca aos oratórios, pode-se observar diversos lugares de exaltação a santos e mitos, 
como os marcadores sagrados de Gauchito Gil em Santo Tomé e de Nossa Senhora dos Navegantes, no bairro do Passo de São Borja (2015).

Nesta região ribeirinha percebe-se diversos espaços sagrados, como: Igreja Imaculada Conceição, santuários de Nossa Senhora de Navegantes, santuário de Iemanjá, Igreja Matriz de São Francisco de Borja, Fonte missioneira de São João Batista (São Borja), Igreja central e santuários de Gauchito Gil e Nossa Senhora de Itatí (Santo Tomé), cemitérios locais, além do rio Uruguai.

Esta região de fronteira possui desde a instalação das Reduções Jesuítico-indígena, uma composição étnica composta por descendentes de indígenas. Após a entrada dos colonizadores espanhóis e portugueses, houve uma maior miscigenação étnica na região. Estas comunidades nativas mantém até hoje ritos, crenças profano-religiosas e imagináios sociais que vem se perpetuando a séculos nestes espaços sociais, tais práticas por muitas vezes acabam mitificando personalidades locais (Pinto 2015).

Os espaços sociais por mais que sejam processos de apropriação, produção e transformação espacial, também envolvem ações de resistência a implementação de novos modos de vida e de novas organizações territoriais. As crenças profanas, religiosas e as ritualidades, ou seja as tradições são práticas sociais que grande valia para os estudos da geografia social.

Para dialogar com este cenário dos espaços sagrados, nos valemos das palavras de Fernandez (1992), este destaca que os espaços sociais historicamente foram construídos a partir da sacralidade e da centralidade. A representação do espaço nas sociedades do passado aparece sobre a forma do sacro-profano (1992).

No caso do recorte estudado, percebe-se que os espaços sacros foram de grande valia para a composição dos espaços sociais regionais, visto que a organização socioterritorial desta região foi influenciada pelas estruturas barrocas das missões. Estas que ocupavam desde então uma localização em centralidades geográficas, como foi o caso da instalação das áreas urbanas das reduções. 
No entanto, se formos discutir hoje como vem sendo constituído os espaços sociais missioneiros, percebe-se que os elementos e manifestações sagradas não estão mais nas centralidades, mas sim nas margens urbanas, o que se mantém ainda nas áreas centrais, são as sedes das igrejas, e os antigos sítios arqueológicos das missões. Cabe destacar, por exemplo que as imaginárias missioneiras do período reducional, encontram-se nas áreas centrais, no entanto estão segregadas em lugares de pouca difusão cultural, como é o caso do Museu Apparício Silva Rillo de São Borja.

A centralidade da sociedade capitalista confere-lhe um duplo caráter (lugar de consumo e consumo do lugar), neste sentido cabe comentar que o centro urbano representa uma "centralidade lúdica" (espaços sociais que constroem as identidades e afirmam as diferenças) (Fernández 1992). Nas últimas décadas espaço tende a resistir a categorização e representação homogênea, a partir da descentralização de ações e vivencias.

Esta relação centro-sacralidade, no que toca as constituições históricas dos espaços sociais, nos permite pensar como as atuais cidades contemporâneas, vem migrando suas práticas e crenças sagradas para as periferias espaciais. Através desta reflexão, instiga-se pensar como a conveniência espacial e suas respectivas alteridades, estão contribuindo para a migração de manifestações tradicionais para as bordas das cidades. Portanto, pode-se relacionar os projetos de modernidades socioespaciais das centralidades, como uma consequência do fortalecimento das manifestações tradicionais das periferias.

Para Fernandez (1992) existe um laço muito forte entre a visão cultural e o campo da existência real (ou sublimada em mito), que constitui o território num espaço sagrado, que se reveste de caráter cósmico e coletivo. Desta mentalidade derivam as representações das cidades santas, dos lugares santos e dos montes sagrados, que dão origem a sagração das igrejas, da benção dos cemitérios e das sepulturas, e da tradicional benção das casas. São assim criados espaços contrapostos ao mundus, isto é, aquilo que é imundo ou impuro (1992).

As palavras de Fernandez (1992), instigam pensar os espaços sagrados através de marcadores cósmicos, que possibilitam refletir sobre como 
os processos de produções culturais interferem nas vivencias e nos imaginários das comunidades. Por muitas vezes as crenças profano-religiosas demarcam um determinado lugar, onde geralmente ocorrem mobilizações coletivas de exaltação espiritual.

Por mais que estes espaços sagrados sejam ritualizados a partir de movimentos coletivos, percebe-se uma composição de uma segregação espacial, que parte da participação, melhor sensibilidade, e reconhecimento popular sobre a real interação deste meio com os processos cósmicos.

Conforme Carballo (2010) a região da Província de Corrientes na Argentina, caracteriza-se pela reformulação dos espaços sagrados a modo católico, como é o caso da devoção de Gauchito Gil, crença popular que convoca a milhares de peregrinos, esta inicia no mês de janeiro na cidade de Mercedes, que recebe entre 200 mil e 250 mil fiéis (2010).

Como se percebe, existem diversos lugares de difusão de práticas profano-religiosas na fronteira, estas que geram relações de pertencimento e narrativas identitárias. Carballho (2010) comenta que as políticas de construção da identidade nacional argentina, se aspiram no binômio ser: argentino e católico. Esta reflexão permite pensar a construção das identidades fronteiriças, a partir das relações de poder exercidas pela Igreja Católica na região.

No que toca aos santuários, foram levantados diversas capelas, estas que exaltam vários santos. Nestes espaços sagrados constantemente entram em cena discursos e simbologias identificadas com as graças recebidas. Entre as capelas da fronteira, os santos que vem sendo mais exaltados são: Nossa Senhora dos Navegantes, Stella Maris ${ }^{1}$ e Gauchito Gil.

Ao refletir sobre os espaços sociais de São Borja-RS, Autor (2015) destaca que a hegemonia socioeconômica gaucha, se constituiu a partir de um conservadorismo religioso católico e social. No entanto, percebe-se

A procissão de Stella Maris foi realizada até 1997, período da construção da ponte, fator este que expõem como a construção desta obra vem contribuindo para perda de práticas sociais e manifestações tradicionais das comunidades ribeirinhas. Cabe de reforçar, que a Procissão de Nossa Senhora dos Navegantes, que se realiza anualmente em São Borja, também deixou de ser ritualizada no rio, após a construção da ponte. 
movimentos de resistência urbana, no que toca as crenças profano-religiosas, assim como na manutenção de práticas sociais tradicionais, como as sociabilidades e modos de vida das comunidades ribeirinhas.

\title{
MARCADORES CULTURAIS MISSIONEIROS NA FRONTEIRA BRASIL E ARGENTINA. REFLEXÕES CONCEITUAIS SOBRE MARCADORES TERRITORIAIS
}

\begin{abstract}
Se a vertente abstracta do simbólico - a transcendência, o divino, a espiritualidade, mas também a ciência, incluindo aqui os sistemas de idéias, de pensamentos, de representações, de crenças - percorre de forma invisível todos os marcadores, é a vertente da materialização que permite a manipulação, tornando visível e palpável os sinais identificadores dos territórios (Henrique 2004: 12).
\end{abstract}

A citação acima de Isabel Henrique destaca que os marcadores territoriais não são constituídos apenas por elementos materializados, mas também por interlocuções que remetem a práticas subjetivas que envolvem topofilias. No entanto, as identificações e relações de pertencimento, constantemente estão sendo alteradas a partir do visível, ou seja, através fabricação de marcadores territoriais.

Joël Bonnemaison (2012), em suas discussões, provoca a reflexão sobre as influências da cultura na constituição dos marcadores territoriais ou dos espaços geosimbólicos descritos. Essas marcas são elementos que contribuem para a interpretação da realidade, uma vez que dão sustentação para a produção dos territórios de vida, convivialidade e enraizamentos sociais. A partir da relação social com tais marcas culturais, observa-se que esses símbolos favorecem os câmbios sociais, históricos, culturais e identitários.

A reflexão sobre a cultura leva a aprofundar o papel do simbólico no espaço. Os símbolos ganham maior força e realce quando se encarnam em lugares. O espaço cultural é um espaço geossimbólico, carregado de afeti- 
vidade e significações: em sua expressão mais forte, torna-se território-santuário, isto é, um espaço de comunhão com um conjunto de signos e de valores (2012: 292).

A partir dessa discussão surge a possibilidade de pensar os marcadores territoriais através das crenças e dos imaginários sociais, que, frequentemente, envolvem a dualidade cognição-materialidade. Conforme Bonnemaison (2012), essas marcas representam uma vertente real negligenciada. Partindo desses pressupostos iniciais, tais marcadores podem ser discutidos como elementos espaciais que contribuem para o reconhecimento socioidentitário regional, pois estão envoltos de ações, símbolos e ideias que interferem na construção das identidades socioterritoriais.

Saquet (2007), ao refletir sobre a apreensão do movimento e da (i) materialidade no território, expõe a necessidade de uma nova compreensão territorial, que se ampara no movimento do e no real e no movimento do pensamento social. Para tanto, discutir as influências das temporalidades espaciais torna-se interessante para a percepção de como o velho é re-criado no novo, movimentos estes que são contínuos e descontínuos.

Os marcadores territoriais envolvem, portanto, elementos espaciais materializados, crenças, ideias e imaginários sociais que representam momentos histórico-culturais vivenciados em determinado espaço social. Essas reflexões expõem uma diversidade simbólica que contribuem para a exposição da realidade social, para a compreensão dos enraizamentos territoriais, para as convivências e para o entendimento dos câmbios socioculturais e históricos (Bonnemaison 2012; Henrique 2004).

Os marcadores territoriais são, portanto, elementos importantes para a melhor compreensão dos processos de construção das identidades socioterritoriais, pois envolvem relações de poder e de pertencimento social. Seus processos de cristalização dependem do tripé cultura-política-espiritualidade. Nessa seara, a vertente imaterial do simbólico traz à tona a transcendência social, enquanto a vertente material torna-se instrumento espacial de alteridade (Bonnemaison 2012; Henrique 2004). 
O conceito de geosímbolos, proposto por Bonnemaison, vem ao encontro das reflexões acerca dos marcadores territoriais. Essa discussão possibilita pensar os geosímbolos como marcas culturais no espaço, os quais expõem as diferenças socioculturais e identitárias, assim como as ações de enraizamento e de alteridade social, ou seja, torna-se um instrumento de comunicação histórico-cultural nos espaços sociais.

Segundo Bonnemaison, o território nasce de pontos e marcas no solo, no centro dele se enraíza o grupo social, enquanto em sua periferia observam-se contornos menos nítidos. Sendo assim, ele está associado tanto à função social quanto à simbólica. Esse aprofundamento conceitual centra-se na importância da imersão subjetiva dos imaginários sociais nas identificações materialistas, que se torna uma crítica às conveniências e relações de poder impostas através da cultura.

Se a vertente abstracta do simbólico - a transcendência, o divino, a espiritualidade, mas também a ciência, incluindo aqui os sistemas de idéias, de pensamentos, de representações, de crenças - percorre de forma invisível todos os marcadores, é a vertente da materialização que permite a manipulação, tornando visível e palpável os sinais identificadores dos territórios (Henrique 2004: 12).

\section{MARCADORES MISSIONEIROS NO PRATA}

Como se observa esta região de fronteira destaca-se por possuir uma localização estratégica na Bacia do Prata, fator este que despertou o interesse da Companhia de Jesus em instalar reduções indígenas na mesopotâmia platina. ${ }^{2}$ A Redução de São Francisco de Borja, destacou-se pela importância social e artístico-cultural nas missões, fator que contribuiu para a produção de inúmeras estruturas arquitetônicas, planos urbanos, e obras artísticas influenciadas pelo barroco renascentista, assim como pela cristalização de crenças profano-religiosas na região.

2 Uma Mesopotâmia pode ser descrita como uma região entre rios. No caso da Mesopotâmia platina, esta entre os rios Paraguai, Uruguai e Paraná. 
Figura 2.

Mapa dos marcadores missioneiros de São Borja-Brasil

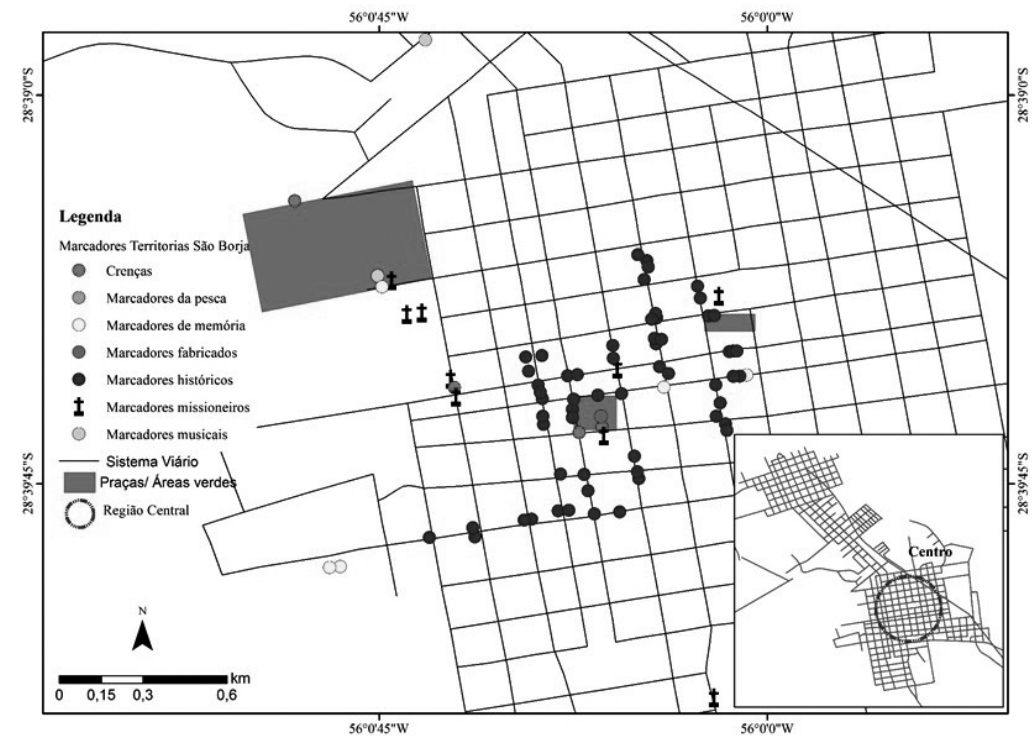

Fonte: (Pinto 2015).

Conforme foi se desenvolvendo a pesquisa de campo, se teve uma melhor compreensão sobre as tipologias dos marcadores territoriais, os quais foram subdivididos conforme sua relação social e territorial com a composição de uma identidade missioneira regional. Conforme a figura acima foram identificados marcadores missioneiros, marcadores fabricados, marcadores de crenças, marcadores ecléticos, marcadores coloniais, marcadores musicais, marcadores de memória, marcadores da pesca, marcadores vivos, entre outros.

A convivência com este momento de grande importância sociocultural e artística, possibilitou a cristalização e fabricação de marcadores culturais materiais e imateriais missioneiros, principalmente nas centralidades fronteiriças. Estas marcas territoriais estão relacionadas a simbologias, práticas sociais e crenças tradicionais, que expõem a organização social, espiritualidade, religiosidade e os processos de construção das 
identidades socioterritoriais regionais. Partindo da premissa imposta pela problemática deste estudo, os marcadores territoriais regionais vem contribuindo para a geração de sentidos, que reproduzem uma identidade missioneira, que ao mesmo tempo é vivida e simbolizada. Esta identidade vem sendo vivenciada através de duas formas sociais, que envolvem marcadores com valores simbólicos segregados e marcadores com valores simbólicos tradicionais.

Para autor (Pinto 2015) após melhor interpretação e reflexão sobre os marcadores territoriais missioneiros sustenta que há influencia de uma ancestralidade tradicional indígena na composição de uma identidade missioneira em São Borja. Estas marcas estão mais presentes nas centralidades espaciais, o que vem ensinado por Fernandez (1992) que destaca que os espaços sociais se constituem a partir da sacralidade e centralidade.

Nestas centralidades percebe-se que há uma sobreposição e articulação com outros marcadores, como os musicais, marcadores de crenças, marcadores de memória, com os marcadores vivos e fabricados, assim como disputam espaço com os marcadores ecléticos e marcadores políticos regionais (Pinto 2015).

Estas marcas vem constituindo fronteiras culturais entre os espaços sociais regionais, uma vez que abaixo das centralidades estão os antigos sítios arqueológicos, além dos processos de segregação das imaginárias missioneiras, que estão em posse de particulares, da igreja e de instituições culturais.

Joël Bonnemaison (2012) instiga em suas discussões refletir sobre as influências da cultura na constituição dos marcadores territoriais, ou dos espaços geosimbólicos descritos pelo mesmo. Estas marcas são elementos que contribuem para a interpretação da realidade, uma vez que dão sustentação para a produção dos territórios de vida, convivialidade e enraizamentos sociais. A partir da relação social com estas marcas culturais observa-se que estes símbolos favorecem os câmbios sociais, históricos, culturais e identitários.

A partir desta discussão surge à possibilidade de pensar os marcadores territoriais através das crenças e dos imaginários sociais, que por 
muitas vezes envolvem a dualidade cognição-materialidade. Conforme Bonnemaison estas marcas representam uma vertente real negligenciada. Partindo destes pressupostos iniciais, estes marcadores podem ser discutidos como elementos espaciais que podem contribuir para o reconhecimento socioidentitário regional, pois estão envoltos de ações, símbolos e ideias que interferem na construção das identidades socioterritoriais.

No que toca a análise dos marcadores culturais missioneiros, deve-se destacar que passados mais de três séculos após a instalação das reduções jesuítico-indígenas na região, percebe-se nas área urbana de São Borja, diversos elementos culturais que remetem ao período reducional missioneiro. $^{3}$

Figura 3. Filtro de água Jesuítico

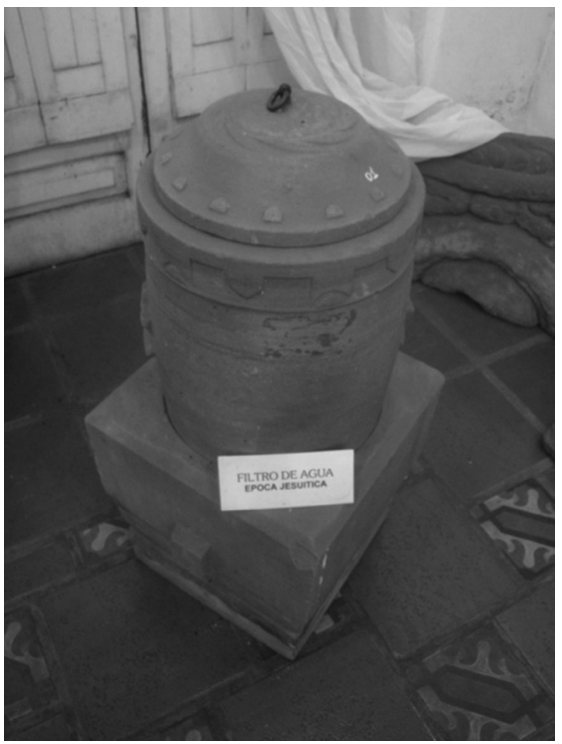

Fonte: Elaboracão do autor. Pinto 2014.

3 Entre estes destaca-se: objetos sacros com características barrocas (imaginárias de santos, pia batismal, e altar); estruturas urbanas (antigo forno, fontes de água natural, resquícios urbanos que foram reutilizados para construções modernas, além das estruturas que estão abaixo subsolo nos sítios arqueológicos da antiga redução). 
Figura 4. Altar missioneiro de São Borja.

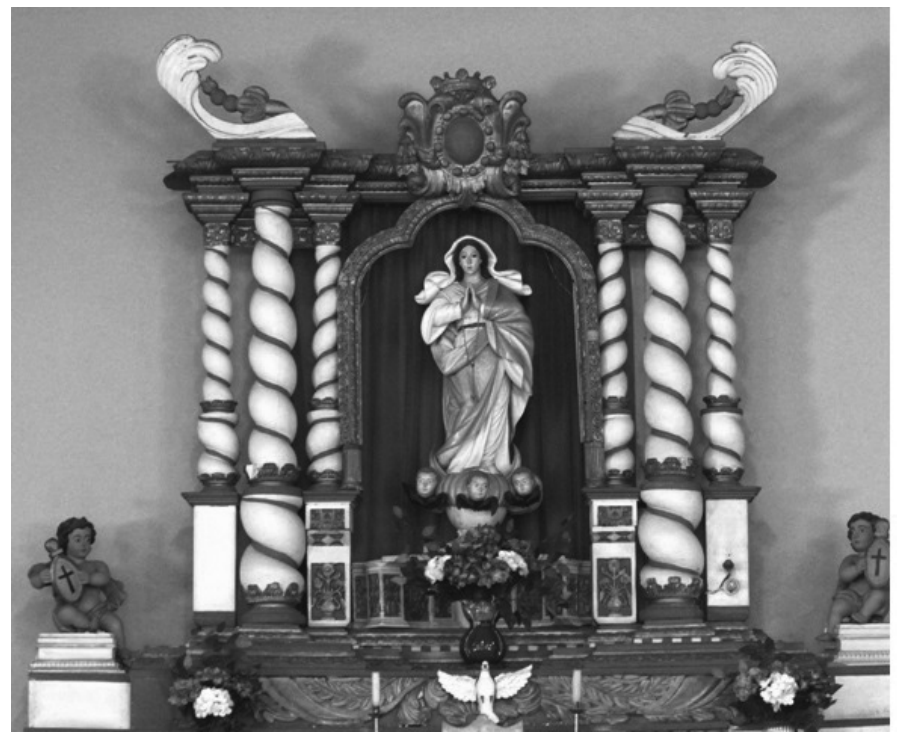

Fonte: Elaboracão do autor. Pinto 2014.

As figuras acima expõe a influência barroca nesta região, tanto a pia batismal, como o altar missioneiro de São Borja, representam marcadores missioneiros tradicionais, que estão em contanto direto com a comunidade. Para autor (Pinto 2015) estas marcas reducionais trazem para a cena urbana, elementos culturais que permitem uma interpretação da realidade vivida através de marcadores identitários que vem transmitindo sentidos s mais de trezentos anos. Como se observa a realidade vivida de São Borja, se firma no espaço e constitui paisagens culturais que representam uma geografia urbana marcada por elementos reducionais.

A grande maioria das imaginárias missioneiras estão distantes de seus locais de sentidos, pois encontram-se em casas de particulares e em museus. Cabe destacar que as estatuárias por muitas décadas estiveram em posse da igreja católica, que utilizava as mesmas como formas de representações sociais. Em virtude destas imaginárias estarem segregadas, visualiza-se uma dificuldade da comunidade local em compreender a real 
contribuição destas artes para o processo de organização social dos territórios regionais.

Figura 5. Missa para São Francisco de Borja.

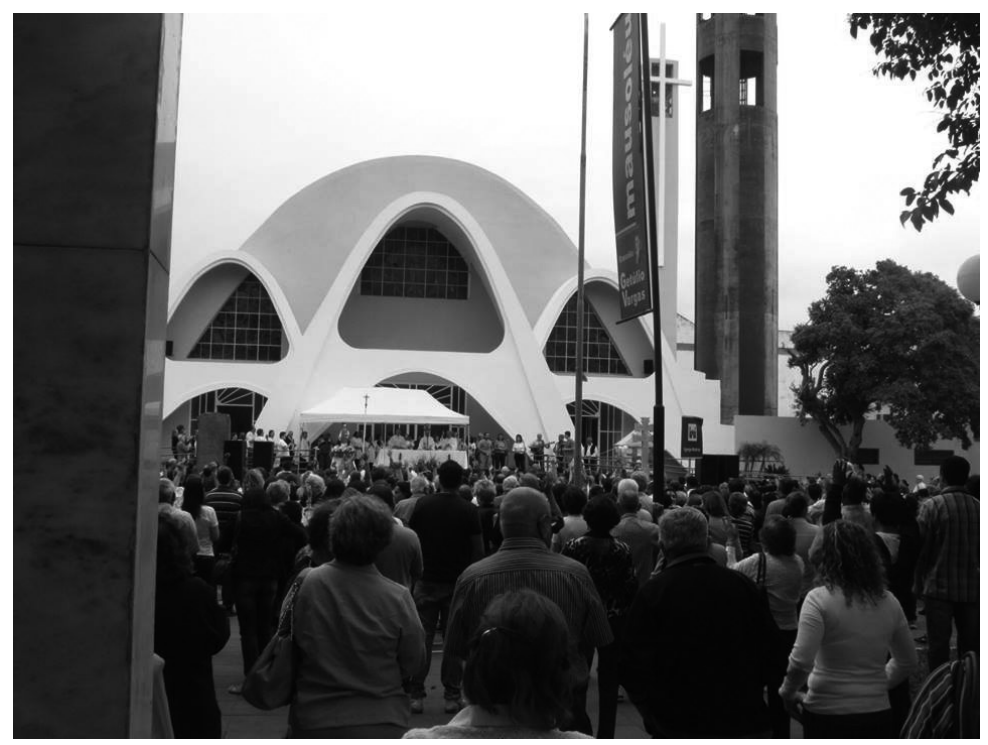

Fonte: Elaboração do autor 2014.

Como já foi comentado anteriormente, na igreja Matriz de São Borja, visualiza-se três elementos do período reducional, como: a pia batismal, e duas imaginárias de São Francisco de Borja. Estes marcadores missioneiros, ainda hoje geram representações sociais para a comunidade católicas da cidade, uma vez que a pia batismal ainda é utilizada para os batismos.

A imaginária de São Francisco de Borja, ${ }^{4}$ elaborada por Brazanelli esta localizada em local estratégico dentro da igreja, esta que leva o nome do padroeiro da cidade. As figuras quatro e cinco representam a Procissão e celebração de exaltação a São Francisco de Borja, celebração que é rea-

4 Conforme Bossegoda (2013), Francisco de Borja de Gandha, era considerado o maior arquiteto barroco jesuíta, este que ajudou a construir Roma. 
lizada anualmente no mês de outubro, que percorre as ruas centrais da cidade. Após a procissão os fiéis retornam para a missa de encerramento, que ocorre na frente da simbólica praça XV de Novembro de São Borja.

\section{Figura 6. Procissão de São Francisco de Borja.}

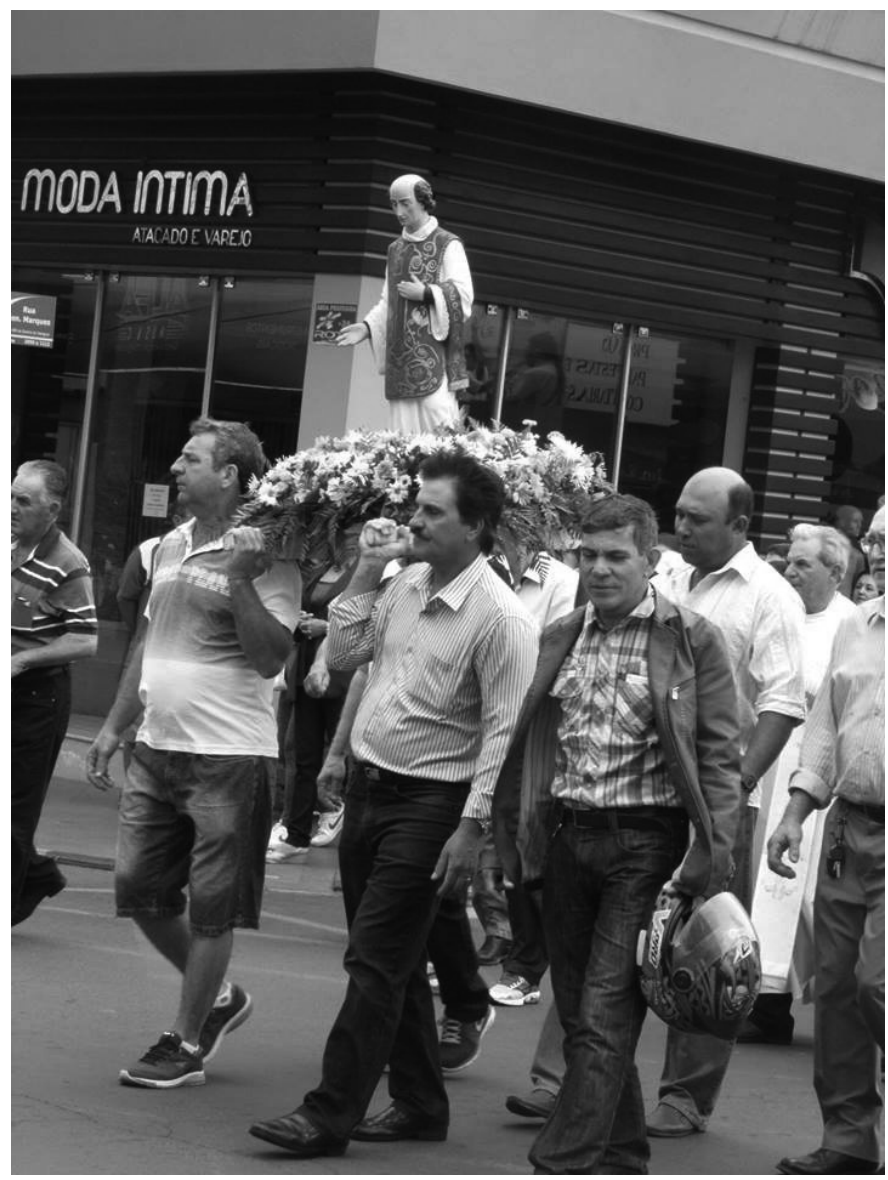

Fonte: Elaboração do autor. 
REPRESENTAÇÕES SOCIAIS E A PRODUÇÃO SOCIAL

DE UMA IDENTIDADE MISSIONEIRA ${ }^{5}$

Revisão de Literatura sobre Representações sociais

Conceitualmente as representações sociais podem ser consideradas formas de conhecimento que expõem saberes práticos sobre as realidades vivenciais. Portanto, são fenômenos cognitivos que envolvem relações de pertencimento, afetividade, normas sociais, interiorização das experiências, das práticas, modelos de conduta e de pensamento (Jodelet 1989).

Jovchelovitch (2009) destaca que as representações sociais estão marcadas pelas relações entre a alteridade, a construção simbólica e o espaço público. Nessa linha de discussão, elas podem ser conceituadas como processos de interpretação, entendimento e construção da realidade dos espaços do cotidiano (Jovchelovith 2009).

Dessa forma, elas não apenas surgem através das mediações sociais, mas expressam por excelência o espaço do sujeito na sua relação com a alteridade, lutando para interpretar, entender e construir o mundo (2009).

Jovchelovitch (2009: 64) entende que as representações sociais representam

o espaço das construções humanas sobre o real, onde a realidade enquanto campo contratual pode ser expandida, redefinida, e eventualmente transformada, exige que repensemos o caráter atribuído à relação entre mundo material e mundo simbólico.

Para Jovchelovitch, as representações emergem como um fenômeno necessariamente colado no tecido social. A análise do campo conceitual das representações nos confronta, no nível do social, com duas dimensões

5 Neste momento da pesquisa foram levantadas e analisadas as representações sociais missioneiras emitidas por diversos grupos sociais regionais. Para tanto, foram levantadas narrativas e paisagens nos seguintes corpus discursivos: discursos dejornais, discursos gerados nas composições e festividades musicais, discursos de instituições públicas, discursos populares e análise das paisagens culturais missioneiras. 
fundamentais da atividade psicossocial: a relação com o ausente e a evocação do possível (2009: 78).

Essa relação entre o ausente e a evocação do possível traz para a discussão as ambiguidades entre os conceitos de representações sociais (envolve elementos simbólicos) e atividade representacional (envolve o lado figurativo, imagético), "onde uma representação é mero reflexo do mundo externo na mente, ou marca da mente que se reproduz no mundo externo" (2009: 65).

Moscovici (2013) propõe pensar as representações sociais através da racionalidade da crença, que, no seu processo construtivo, devem ser levadas em conta na medida em que são coletivas, pois, conforme o autor, é através da coletividade que os homens tornam-se racionais.

Para Moscovici, a análise dos conflitos entre os sentidos individualizados e os sentidos coletivos inseridos nas representações sociais são reflexões que devem ser contempladas nas análises dos espaços sociais. As disputas pelos sentidos são ações que fazem parte da vida social e, nessas arenas, as representações buscam incorporar o mundo social no mundo individual; a negação desses conflitos gera visões estáticas dos processos sociais.

Nos últimos anos percebe-se no Brasil a ascensão das discussão sobre as relações das representações sociais com a produção social do espaço. Heidrich (2013), instiga a reflexão sobre a produção de sentidos sociais a partir das análises culturais, através da articulação forma-ação-representação e suas interferências territoriais. Nessa tríade analítica, as formas, quando relacionadas com as ações e representações sociais repetitivas, tornam-se modalidades abstratas, singulares no espaço, e essas morfologias são criadas a partir das ações de construção e transformação espacial (2013).

Gostaria, nesse sentido, de registrar três aspectos que envolvem a noção de que as territorialidades humanas implicam em certa inseparabilidade das dimensões do que é humano, do que se expressa na sua materialidade objetiva: (a) constituindo um poder, uma ocupação, (b) como reprodução da vida que implica no agir e (c) como sua representação. Mesmo quando se desenrolam a partir de distintas instâncias ou dimensões da sociedade, 
provocam relações que abarcam realidades integrais das sociedades e dos sujeitos. O território e a territorialidade expressam, como uma feição da(s) geografia(s), essa condição inteira, completa, que se refere ao complexo forma-ação-representação (2013: 59).

As palavras de Heidrich (2013) procuram expor como as análises dos marcadores materializados no espaço podem ser realizadas de forma recíproca entre o conhecimento da externalidade e da realidade subjetiva do concreto. Para tanto, necessita-se compreender os objetivos da materialização e suas relações com os processos de conceber as simbologias culturais.

Nessa lógica, as análises das territorialidades humanas devem respeitar as articulações interpretativas entre o concreto e subjetivo, pois elas geram poder espacial, reprodução de vivências que influenciam no agir e na reprodução de representações, fatores que transparecem realidades integrais (Heidrich 2013).

As abordagens geográficas, principalmente as relacionadas à Geografia Cultural, refletem as representações sociais como instrumentos de pesquisa para as análises sociais do espaço. Heidrich (2010, 2014), ao pensar as representações sociais através de uma abordagem territorial, enfatiza que elas se tornam uma colagem do social no espaço apropriado, suas elaborações criam morfologias que requerem noções de espaço.

Nesse processo de produção e reprodução das representações, constantemente entram em cena elementos autênticos e fabricados, que necessitam de uma comunicação sociocultural para a melhor compreensão do vivido (Heidrich 2010, 2014).

A noção, a ideia em sentido amplo, e o conceito, a concepção precisamente elaborada, estabelecem vínculos fundamentais com o campo cultural, o campo da criação, da compreensão do vivido. Viver implica em representar e ao mesmo tempo transgredir a própria representação, tem a ver com a produção de significados (2010: 2).

Essa reflexão de Heidrich (2010) estimula a pensar as representações vivenciais a partir do campo cultural e dos espaços de vida. Tais compreensões tornam-se mais reconhecíveis em comunidades pequenas e 
tradicionais, no entanto essa modernidade complexa vem re-elaborando as representações coletivas conforme seus interesses.

As palavras de Heidrich contribuem para a reflexão sobre como vêm sendo produzidas as representações identitárias missioneiras. Ao longo dos últimos trezentos anos, observa-se que essas produções sociais vêm perpetuando práticas artísticas que se tornam mediadoras entre as vivências cotidianas e as vivências passadas.

A análise das representações sociais nos coloca diante da necessidade de decodificar este mundo próprio do Universo banal, o do ser no espaço para o ser enquanto espaço. Partimos das representações sociais para uma geografia cultural do mundo banal, da cultura cotidiana, do Universo consensual, impactada pelo Universo reificado da ciência e da política (Gil Filho 2005: 50).

O autor destaca que o universo reificado está amparado pela ciência e pela política, enquanto o universo consensual está constituído a partir de relações com o cotidiano, que "projeta as pessoas diante dos dilemas da vida através da busca de aparatos míticos e rituais que envolvem o mundo enquanto convenções" (Gil Filho 2005: 51).

No que diz respeito às representações sociais, Rosemberg (2003) destaca que elas esclarecem os comportamentos de quem as escolhe, pois estão relacionadas às práticas sociais e representam realidades indistintas, discussões estas que instigam a pensar as representações missioneiras geradas por populares descendentes nativos da região.

No decorrer de sua discussão, Rosemberg traz para o debate a possibilidade de discutir criticamente as relações de poder nas representações, uma vez que defende a liberdade do sujeito como uma forma de renovação da "responsabilidade pessoal", valoriza as diferenças culturais como um fator de equivalência dos saberes, realiza uma crítica ao modelo cultural generalizado, assim como propõe uma análise dos novos usos espaciais a partir das representações.

O que está em jogo de forma implícita dentro da afirmação que une equivalência dos saberes/ olhares que postulam a liberdade. A liberdade do sujeito renova sua "responsabilidade pessoal": pois possibilita trocas que 
poderão redescrever e redefinir sua própria personalidade. A descrição engrossada de fatos culturais como fim em sua compreensão dão a seguinte perspectiva: faz emergir as representações, suas mudanças e comportamentos. A liberdade humana, não como um objeto de reflexão a opor o determinismo espacial, mas como um postulado fundador da equivalência dos saberes, abolindo a porte social do saber geográfico. Cada um num intervalo de tempo e espaço livre (Rosemberg 2003: 74).

O raciocínio de Rosemberg desperta para a autonomia de pensamento dos atores territoriais no que diz respeito à constituição de seus saberes e suas representações identitárias, que podem interferir na composição de sua personalidade e consciência socioterritorial.

\section{Representações sociais fronteiriças}

Ao analisar as representações sociais fronteiriças, Pinto (2015) destaca que por muitas vezes entram em cena imaginários que exaltaram a cultura tradicional indígena, nestes discursos foram destacados os sítios arqueológicos e antigas estruturas urbanas reducionais como os legítimos territórios culturais missioneiros.

Segundo Pinto (2015: 182),

A partir da análise discursiva e simbólica percebe-se que cotidianamente são reproduzidas paisagens culturais que representam as crenças sagradas regionais. Nestas representações foram gerados imaginários sociais que remeteram sobre a importância dos sítios arqueológicos reducionais, assim como surgiram narartivas sobre a existência de subterrâneos das antigas igregas das missões. No decorrer das narrativas foram expostas representações míticas de exaltação e disputa simbólica pela figura do líder Guarani Andresito Guacurari Artigas.

Durante as narrativas levantadas foram identificadas manifestações populares em defesa da valorização e preservação do patrimônio arqueológico missioneiro, que representaram ações de autonomia nos processos de construção da identidade missioneira. Também foram emitidas representações de resistência as alteridades político ideológicas que vem justapondo marcadores culturais sobre os remanescentes missioneiros. 
Figura 7. Iconografia do Grupo Artístico Os Angueras.

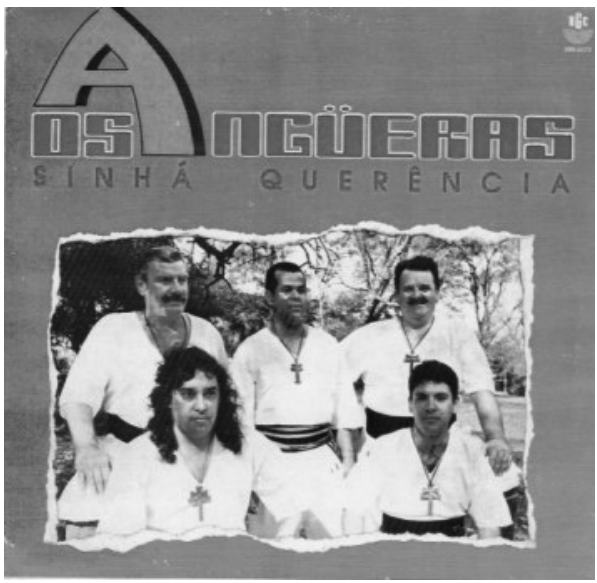

Fonte: Centro Nativista Boitatá.

Figura 8. Iconografia da comparsa de samba Marabú de Santo Tomé

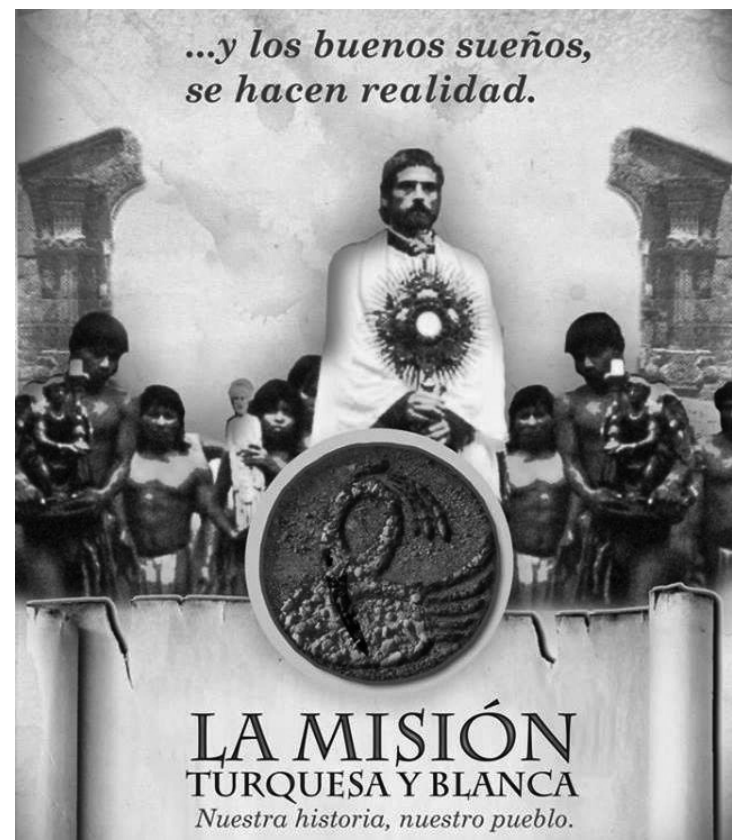

Fonte: Journal Digital Santo Tomé. 
A partir da análise dos diversos corpus discursivos levantados pelo estudo, foi possível uma melhor compreensão de como vem se constituindo as narrativas identitárias missioneiras através de representações sociais identificadas com as missões. Neste sentido, percebe-se que os imaginários populares de São Borja, reconhecem e valorizam uma influência tradicional indígena nos processos identitários regionais, estes que conforme as imagens acima vem sendo representados em iconografias de centro nativistas, em iconografias de grupos artísticos (figura 7), nos discursos jornalísticos e em iconografias de comparsas carnavalescas (figura 8).

Para Pinto (2015) a identidade missioneira vem se cristalizando na região a partir de representações sociais que demarcam um enraizamento sociocultural tradicional que vem sendo vivenciado, reconhecido e pertencido nos espaços arqueológicos pertencentes à antiga Redução de São Francisco de Borja.

Nesta perspectiva percebe-se que a produção das representações identitárias missioneiras vem sendo constituídas a partir de vínculos socioespaciais com os marcadores sagrados e artísticos, que constantemente afirmam a valorização da influência tradicional Guarani nos processos de construções identitárias regionais (Pinto 2015).

A reflexão sobre as representações sociais missioneiras contribuíram para a compreensão de que a identidade missioneira constantemente se legitima, a partir de territorialidades e imaterialidades vivenciadas sob espaços sociais que nos últimos trezentos anos destacam-se por reproduzir arte, espiritualidades, religiosidades, ritualidades, misticismos, e conhecimento ecocultural da biodiversidade do rio.

A articulação entre as reflexões sobre os espaços sociais e marcadores territoriais missioneiros, possibilitaram uma melhor compreensão de como as representações sociais regionais vem contribuindo para os processos de construção de uma identidade missioneira em São Borja. Tal linha de pensamento apresenta um mundo social missioneiro, que constantemente vem produzindo sentidos a partir de imaginários sociais que passam a produzir representações identitárias missioneiras. Estas 
produções sociais passam a reproduzir nos espaços do cotidiano, um mundo social missioneiro marcado por modos de vida e relações sociais tradicionais.

Nesta linha de discussão, sustenta-se que os marcadores identitarios missioneiros se legitimam, a partir de influências ancestrais e heranças socioculturais, que demarcam um enraizamento social através da manutenação de crenças sagradas e pela produção da arte.

Sendo assim, as narrativas sociais regionais, reafirmam a compreensão de que os marcadores urbanos reducionais existentes em São Borja, até hoje servem como elementos culturais que contribuem a pratica de uma identidade missioneira contemporânea, entre estes foram destacados os sítios arqueológicos e antigas estruturas urbanas reducionais como legítimos territórios culturais missioneiros.

Além das crenças sagradas, a musicalidade regional foi representada como conhecimentos artísticos tradicionais que estão sendo reproduzidos desde a temporalidade das reduções Jesuítico-Guarani. A realização dos festivais e das coletividades musicais, destacam as musicalidades como produções do vivido que remetem aos enraizamentos tradicionais missioneiros na comteporaneidade.

Nesta linha de pensamento, percebe-se que o tempo histórico do período reducional, até hoje vem reproduzindo sentidos que contribuem para a afirmação de uma identidade missioneira. No entanto, cabe destacar que a falta de compreensão dos câmbios socioculturais missioneiros, perante outras identidades regionais, acabam escondendo os enraizamentos sociais tradicionais na composição de uma identidade misisoneira em São Borja. Desta forma os conhecimentos socializados através da música regional, despertam uma realidade escondida nas representações sociais das Missões.

Nas narrativas analisadas destacaram-se representações sociais que exaltam a figura de Andresito Guacurari Artigas, como o legitimo herói Guarani regional. Estes imaginários sociais possbilitam pensar este nativo como um marcador identitário que legitima a partir de uma representação mítica. 
Estas representações míticas reforçam reconhecimentos das missões através de rememorizações e exaltações da figura de um nativo Guara$n i$, por parte das comunidades nativas e dos órgãos públicos fronteiriços. Como principal ato de exaltação mítica de Guacurari, destaca-se a luta regional, para a intitulação deste como Herói Nacional Argentino, no ano de 2013.

No decorrer das narrativas foram identificadas relações de diferença entre as municipalidades de São Borja e Santo Tomé, a partir de disputas territoriais sobre o local de nascimento de Guacurari. Estas representações sociais demontram um fortalecimento do pertencimento identitário local, que consolidaram artifícios legais para inserir um marcador identitário missioneiro regional, como um elemento de identidade nacional argentina.

Seguindo nesta linha de raciocionio, cabe destacar que a reflexão sobre as representações sociais, permite pensar a produção social da escultura, da música e a reprodução das crenças sagradas e míticas, como elementos centrais na construção de uma identidade missioneira. A análise destes corpus discursivos, dão sustentação para pensar estas produções sociais como transcendências espirituais e topofílicas nos processos identitários das Missões.

Neste contexto discursivo, foram notadas ações de autonomia popular nos processos de construção da identidade missioneira regional, que expuseram intenções de novas descobertas arqueológicas, que resultaram em vozes em defesa de escavações arqueológicas nos centro histórico de São Borja.

Através destas narrativas são reforçadas representações que questionam a necessidade de valorização e proteção dos remanescentes urbanos da antiga Redução de São Francisco de Borja. Estes imaginários na sua grande maioria foram emitidos por populares, que cotidianamente buscam novos sentidos sociais para as antigas áreas reducionais, como foram os relatos de existência de túneis subterrâneos abaixo da praça central da cidade. 
Esta praça que por muitas vezes, vem sendo uma territorialidade de disputa simbólica, entre as identidades trabalhista e missioneira. Portanto, este antigo espaço social reducional, contribui para representações de resistências as alteridades político-ideológicas regionais, que preferem exaltar e justapor os marcadores identitários trabalhistas, em relação aos marcadores identitários missioneiros que estão abaixo do subsolo.

Como se observa as representações sociais missioneiras, por algumas vezes demarcaram resistências a uma hegemonia sociocultural da estância e das ideologias sociopolíticas do trabalhismo na constituição das identidades regionais, ou seja, as representações de exaltação as missões salientam-se como contra-narrativas aos sentidos objetivados e reificados de homogeinização identitária gaucha-trabalhista em São Borja.

Portanto, torna-se compreensível as relações de forças e câmbios socioculturais entre a cultura missioneira e gaucha. Através da musicalidade missioneira, percebe-se influencias nativas indígenas na produção desta arte. Através deste cenário representacional, que a identidade missioneira vem se constituindo através de formas hibridas e ao mesmo tempo de forma autêntica.

Para finalizar a reflexão deste capitulo, observa-se nas representações sociais missioneiras elementos culturais e imaginários sociais, que transcrevem a construção da identidade missioneira, através de depois mundos representacionais, um autêntico e consensual, vinculado as autenticidades reducionais, e outro hibrido e reificado, socializado através de trocas culturais e fabricações sociais da cultura gaucha estancieira.

\section{CONSIDERAÇÕES FINAIS}

A devida pesquisa teoricamente centrou suas reflexões na área da Geografia Social, no entanto suas reflexões dialogaram com outras áreas do conhecimento, como: geografia cultural, geografia da Religião, psicologia social, historiografia regional, estudos culturais, análise do discurso, filosofia da religião, sociologia, antropologia, entre outras. 
No que toca as contribuições deixadas por esta pesquisa, para futuras estudos sobre os espaços sociais regionais, destaca-se que a partir de uma análise socioterritorial das comunidades tradicionais ribeirinhas e comunidades estancieiras, apresenta-se uma reflexão geoetnográfica dos espaços das crenças sagradas e suas relações com os marcadores culturais e representações sociais missioneiras nesta região histórica do Prata. Para tanto, foram utilizadas literaturas nacionais brasileiras e do exterior, principalmente.

Nesta pesquisa percebe-se através do diálogo das marcas missioneiras com as comunidades regionais, uma constante produção de sentidos através da constituição de imaginários sociais. Portanto, sustenta-se neste estudo que os marcadores reducionais (antigas estruturas urbanas e imaginarias sacras) ainda mantém forte vinculação socioespacial com as práticas sociais tradicionais e com as crenças sagradas e míticas.

A partir da análise extensiva de corpus discursivos regionais, foram interpretadas as representações sociais vinculadas às missões, estas expuseram narrativas de pertencimento identitário missioneiro. Defende-se nesta pesquisa, que vem havendo uma retomada das representações missioneiras através de ações sociais populares, estas narrativas civis reforçam um reconhecimento socioterritorial regional sobre a importância histórica e cultural do período reducional, que vem gerando novos processos de sentidos.

Nestas representações foram emitidos discursos de valorização dos sítios arqueológicos e de critica a padronização de sentidos regionais com interesses ideológicos e econômicos. Portanto, percebe-se as representações missioneiras como fatores de resistência, a negação identitária nativa tradicional, e como contra-narrativas aos processos de coesões de sentidos, pois constantemente observa-se vozes comunitárias de proteção e preservação do patrimônio cultural missioneiro regional.

Sendo assim, esta pesquisa procurou entender os processos identitários missioneiros através de realidades cotidianas que vem se perpetuando a mais de três séculos nestes espaços sociais. Esta busca pela praticas tradicionais missioneiras foram reveladoras nesta pesquisa, pois expôs 
marcas identitárias que por muitas vezes estão ausentes e excluídas dos processos de reconhecimento, pertencimento e produção de sentidos nas missões.

Após as reflexões geradas sustenta-se a tese que a identidade missioneira da região de São Borja (Brasil)-Santo Tomé (Argentina), por mais venha sofrendo constantemente com alteridades impostas por relações de força política, ideológica e econômica advindas das centralidades estancieiras, ainda mantém práticas tradicionais enraizadas nas vivencias nativas.

Estas vivências estão constantemente articuladas com os remanescentes urbanos e artísticos do período reducional. Através da análise das redes territoriais e das representações sociais, se sustenta que a produção de sentidos do mundo social missioneiro das margens do rio Uruguai, se legitima a partir de ritualidades, crenças sagradas, míticas, e através da cristalização discursiva e simbólica da musicalidade missioneira. Estes marcadores identitários missioneiros se utilizam das materializações culturais como artifícios de transcendência espiritual e cultural, que vem sendo reproduzidos pelas identidades ribeirinhas e gaucha.

Para tanto, sustenta-se nesta pesquisa que os processos identitários regionais apresentam uma identidade missioneira que ao mesmo tempo é vivida e simbolizada nas áreas urbanas destas cidades. A análise dos imaginários sociais, territorialidades culturais e das paisagens culturais missioneiras, revelam as crenças como os principais elementos socioterritoriais de construção da identidade missioneira.

Estes marcadores nos permitem pensar a identidade missioneira como sagrada, pois envolvem processos de identificação e reconhecimento socioespacial através de mitificações. Estas mediações representam como ela esta enraizada de forma tradicional em diversos modos de vida fronteiriços, ou seja, a construção identitária regional se cristaliza no território através de um dialogo das práticas sociais tradicionais com os remanescentes urbanos.

Sendo assim, destaca-se que a identidade missioneira se constitui em São Borja, através do compósito de marcadores materiais e imateriais, representações sociais, e de referências geográficas e históricas. Este con- 
junto de referências missioneiras contribuem para a junção das vivencias, sendo assim a identidade missioneira, por muitas vezes se torna nublada e complexa, em virtude da trama das realidades vividas.

Para finalizar torna-se prudente reforçar que as temáticas discutidas neste estudo os marcadores culturais, espaços sagrados e representações identitárias missioneiras são de grande valia para o momento atual do planejamento e gestão das políticas culturais da devida região histórica, visto que as duas áreas urbanas das cidades de São Borja-Brasil e Santo Tomé-Argentina estão sobrepostas com os sítios arqueológicos das antigas Reduções Jesuítico-Guarani. Tais reflexões poderão contribuir com a gestão do Sítio Arqueológico de São Francisco de Borja, chancelado pelo Instituto do Patrimônio Histórico e Artístico Nacional e solicitado registro no Conselho nacional de Arqueologia (CNA) do Brasil no recente ano de 2018.

\section{REFERÊNCIAS}

BONNEMAISON, JoËL. "Viagem em torno do território", em Roberto Lobato Correa e Zeny Rosendhal, Geografia cultural: uma antologia. Rio de Janeiro: Euderj, 2012.

Bossegoda, Bonaventura. "La iconografia de Sant Francesc de Borja: Una primera aproximació a partir de L'estampa”. Revista Borja 4 (2013).

Carballo, Cristina Teresa. "Hierópolis como espacios en construcción: las práticas peregrinas en Argentina". Rosendahl, Zeny, Trilhas do sagrado, Rio de Janeiro: Eduerj, 2010.

FERnandeZ, Antonio Teixeira. "Espaço social e suas representações". Revista da Faculdade de Letras Sociologia 2 (1992): 61-99.

Gil Fillho, Sylvio Fausto. "Geografia cultural: estrutura e primado das representações". Revista Espaço e Cultura 19-20 (2005): 51-59.

HEIDRICH, ÁLVARO. "Território e cultura: Argumento para uma produção de sentido". Álvaro Heidrich, Benhur Pinos Da Costa e Cláudia Luisa Zeferino Pires, Maneira de ler: Geografia e Cultura. Porto Alegre: Imprensa Livre: Compasso Lugar e Cultura, 2013. 
HEIDRICH, ÁLVARO. "A abordagem territorial e noção de representação". XVI ENG-Encontro Nacional de Geógrafos, Porto Alegre, 2010.

Henrique, IsABel CASTRO. "A materialidade do simbólico: marcadores territoriais, marcadores identitários angolanos (1880-1950)", Textos de História 12. 1/2 (2004).

JODELET, D. "Représentations sociales: un domaine en expansion". D. Jodelet (ed.), Les représentations sociales. Trad.Tarso Bonilha Mazzotti. Paris: PuF, 1989. 31-61.

JOVCHELOVITCH, SANDRA. "Vivendo a vida com os outros: intersubjetividade, espaço público, e representações sociais". Pedrinho Guareschi e Sandra Jovchelovitch, Textos em representações sociais. Petrópolis: RJ Vozes, 2009.

Moscovici, Serge. "Prefácio de Textos em Representações Sociais". P. Guareschi e Jovchelovitch (org.). Textos em Representações Sociais. Petrópolis: Vozes, 2013.

MuRIEL, PINTO. A identidade socioterritorial missioneira da cidade histórica de São Borja-RS: as hegemonias de poder sobre uma identidade tradicional enraizada entre antigas reduções Jesuítico-Guarani. Porto Alegre: Programa de Pós-Graduação em Geografia, (Tese de Doutorado), 2015. Disponível em: https://www.lume.ufrgs.br/ bitstream/handle/10183/131160/000980214.pdf?sequence $=1$

RosemberG, Muriel. Contribution à une réflexion géographique sur les représentations et l'espace, Geocarrefour 78/1 (2003).

SAQUET, MARCos AurÉLIO. "As diferentes abordagens do território e a apreensão do movimento e da (i) materialidade". GeoSul 22.43 (2007): 5-76.

Os Angueras. Grupo Amador de Arte. Disponível em http://www.angueras.com.br/historico.htm (acesso em 12 de novembro de 2014). 